\title{
Targeting the PI3K/Akt pathway in prostate cancer: Challenges and opportunities (Review)
}

\author{
PAUL TOREN and AMINAZOUBEIDI \\ The Vancouver Prostate Centre, Department of Urologic Sciences, University of British Columbia, \\ Vancouver, British Columbia V6H 3Z6, Canada
}

Received May 9, 2014; Accepted July 4, 2014

DOI: 10.3892/ijo.2014.2601

\begin{abstract}
The PI3K/Akt pathway is an actively pursued therapeutic target in oncology. In prostate cancer, the activation of this pathway appears to be characteristic of many aggressive prostate cancers. Further, activation of the PI3K/Akt pathway is more frequently observed as prostate cancer progresses toward a resistant, metastatic disease. Signalling from this pathway activates numerous survival, growth, metabolic and metastatic functions characteristic of aggressive cancer. Biomarkers of this pathway have correlated activation of this pathway to high grade disease and higher risk of disease progression. Therefore there is significant interest in developing effective strategies to target this pathway in prostate cancer. In this review, we discuss the pre-clinical and clinical data relevant to targeting of the PI3K/ Akt pathway in prostate cancer. In particular, we review the rationale and relevance of co-targeting approaches against the $\mathrm{PI} 3 \mathrm{~K} / \mathrm{Akt}$ pathway. It is anticipated that through an improved understanding of the biology of the PI3K/Akt pathway in prostate cancer, relevant biomarkers and rationale combination therapies will optimize targeting of this pathway to improve outcomes among patients with aggressive prostate cancer.
\end{abstract}

\section{Contents}

1. Introduction

2. PI3K/Akt signalling pathway

3. Regulation by phosphatases

4. Role of PI3K/Akt in prostate carcinogenesis and progression

5. PI3K/Akt and the AR pathway

6. PI3K/Akt pathway as a biomarker in prostate cancer

7. Clinical studies of PI3K/Akt/mTOR inhibitors in prostate cancer

8. Combination targeting in prostate cancer

9. Conclusion

Correspondence to: Dr Amina Zoubeidi, The Vancouver Prostate Centre, 2660 Oak Street, Vancouver, BC V6H 3Z6, Canada

E-mail: azoubeidi@prostatecentre.com

Key words: PI3K, Akt, mTOR, prostate cancer, resistance, combination therapy

\section{Introduction}

Prostate cancer is the second most frequent cause of cancer death in American men, with approximately 1 in 36 men dying of prostate cancer (1). Over the last several years, new therapies have emerged for treatment of castrate resistant prostate cancer (CRPC) which have improved the survival of patients with this disease $(2,3)$. Nonetheless, cure remains elusive with resistance developing over time. With the increasing use of potent anti-androgens such as abiraterone and enzalutamide, there is renewed interest in targeting non-AR pathways in prostate cancer progression.

One of the most prominent alternate pathways in prostate cancer is the PI3K/Akt signalling pathway. Activation of this pathway is implicated in many aggressive human cancers (4). Accordingly, there has been significant investment toward developing targeted inhibitors of this pathway in various hematologic and solid cancers. In this review, we will discuss the relevance of the PI3K/Akt pathway in prostate cancer, highlighting both basic science and clinical aspects.

\section{PI3K/Akt signalling pathway}

The PI3K/Akt signalling pathway regulates cellular metabolism, tumour development, growth, proliferation, metastases and cytoskeletal reorganization. It is part of a complex intracellular cell signalling cascade (Fig. 1). PI3K is a plasma membrane-associated protein kinase consisting of three subunits: the regulatory subunits p 85 and p55; referred by convention as collectively p85 and a catalytic subunit, p110 (5). There are three classes; it is the class IA PI3Ks which are the most clearly implicated in human cancer, including prostate cancer. Moreover, this class is usually downstream of receptor tyrosine kinases. Activation of receptor tyrosine kinases at the cell membrane results in conformational changes which removes auto-inhibition of the catalytic domain of PI3K. Three catalytic isoforms $\mathrm{p} 110 \alpha, \mathrm{p} 110 \beta$ and $\mathrm{p} 110 \delta$ are, respectively, the product of the genes PIK3CA, PIK3CB and PIK3CD. Once activated, PI3K catalyzes the phosphorylation of PIP2 to produce PIP3. PIP3 then activates intracellular signalling through its binding to pleckstrin homology $(\mathrm{PH})$ domains of many signalling proteins, including Akt. In prostate cancer, it appears that the p110 $\beta$ isoform is most relevant to prostate 
cancer progression and resistance (6). It has been associated with basal activation of Akt in prostate cancer models (7).

The PI3K/Akt pathway functions downstream of receptor tyrosine kinases (RTKs) as well as independently of RTKs. Non-RTK activation of this pathway may be from other intracellular signalling pathways or from other membrane receptors including G-protein coupled receptors. The main upstream activators likely are context specific. In autopsy specimens of metastatic prostate lesions, various RTKs were associated with Akt activation (8). Of note, many of the RTKs which activated the PI3K/Akt pathway, including EGFR, IGF-IR, FGFR and c-MET receptors, are actively researched as targets in CRPC. Nonetheless, some in vitro studies in prostate cancer cells suggests that basal activation of this pathway occurs independently of RTKs (7). Notably, phospho-proteomic analysis of metastatic tumour samples collected on rapid autopsy found that Akt was the tyrosine kinase most commonly found to be active in metastastic prostate cancer (8). Activated Akt is a kinase which in turn phosphorylates and activates many oncogenic features within cancer cells. Upon recruitment to the cell membrane, it is phosphorylated by phosphoinositide-dependent kinase 1 (PDK1), a reaction catalyzed by PIP3 binding to the PH domains of both molecules (Fig. 1). Once phosphorylated at both Ser473 and Thr308 phosphosites, the activated Akt can activate many downstream functions via its kinase activity.

Mammalian target of rapamycin (mTOR) is a major downstream signalling protein involved in protein translation via the eIF4E complex and S6K which is activated by Akt. Both mTOR and S6K are found in higher levels in prostate cancer compared to benign controls (9). The proteins differentially associated with mTOR defined the TORC1 andTORC2 complexes. These have overlapping, but different functions, with TORC2 providing negative feedback regulation on the PI3K/Akt pathway via S6K $(10,11)$. There are many other downstream oncogenic effects of Akt phosphorylation. Cell survival is promoted through antiapoptotic effects, particularly inhibition of the pro-apoptotic Bcl-2 family members BAD and BAX (12). Transcription factor FOX01 acts as a tumour suppressor and its phosphorylation by Akt induces its ubiquitation and degradation by the proteasome. Further, inhibition of glycogen synthase kinase 3 (GSK-3) increases cellular translation of proteins as does phosphorylation of 4eBP-1. Regulation of cell growth and survival by Akt also occurs by the NF- $\mathrm{B}$ pathway via activation of IאB kinase (IKK) (Fig. 1). Further, the PI3k/Akt pathway in prostate cancer appears to be involved with modulation of DNA damage repair pathway (13). More recently, the PI3K/Akt pathway has been implicated in modulating a more aggressive phenotype through modulation of cholesterol ester formation in prostate cancer cells (14). This suggests a possible relationship with metabolic pathway disturbances and the development of aggressive prostate cancer. Overall, there are a plethora of downstream cellular functions of the Akt pathway which correspond to a clinically aggressive phenotype.

\section{Regulation by phosphatases}

The PI3K/Akt pathway is antagonized by several phosphatases, including phosphatase and tensin homolog gene (PTEN), PH and leucine-rich repeat protein phosphatase (PHLPP), cellular prostatic acid phosphatase, PP2A and INPP4B (15-17) (Table I).
Table I. Common genomic alterations potentially involved in activation of the $\mathrm{PI} 3 \mathrm{~K} / \mathrm{Akt} / \mathrm{mTOR}$ pathway from the MSKCC dataset (47).

\begin{tabular}{lccc}
\hline Gene & Type of alteration & $\begin{array}{c}\text { Prevalence } \\
\text { in metastatic } \\
\text { disease }(\%)\end{array}$ & $\begin{array}{c}\text { Prevalence } \\
\text { in localized } \\
\text { disease }(\%)\end{array}$ \\
\hline PTEN & Loss or inactivation & 4 & 42 \\
INPP4B & Loss or inactivation & 8 & 47 \\
PIK3R1 & Loss or inactivation & 22 & 58 \\
PIK3R3 & Loss or inactivation & 2 & 16 \\
PIK3CA & Activating mutation & 6 & 16 \\
PHLPP & Loss or inactivation & 11 & 37 \\
\hline
\end{tabular}

Genetic loss or other inactivation of these phosphatases results in greater amounts of phospho-Akt and subsequent increased or sustained oncogenic signaling. Notably, the PTEN gene on chromosome $10 \mathrm{q} 23.3$ is the most-commonly deleted gene in prostate cancer (18). However, genomic loss of PTEN does not always correlate with activation of the PI3K/Akt pathway (19). Pre-clinical models and patient samples also show that loss of PTEN results in a particularly aggressive phenotype when found in combination with activation of receptor tyrosine kinases $(20,21)$. PHLPP is regulated by the AR via FKBP5 and explains in part the upregulation of the PI3K/Akt pathway seen following androgen deprivation (17). INPP4B is decreased following androgen deprivation and may be another mechanism through which the Akt pathway is activated resulting in earlier disease recurrence (16).

\section{Role of PI3K/Akt in prostate carcinogenesis and progression}

The mechanisms through which the PI3K pathway may induce carcinogenesis include the activation of growth and survival pathways. Further, activation of this pathway may also alter epigenetic regulators, such as BIM1 (22). The PI3K/Akt pathway has also been shown to be important to the survival and proliferation of prostate cancer stem cells (23).

PTEN deletion is commonly used to model prostate cancer progression in mice $(24,25)$. PTEN loss in mice has been shown to suppress androgen-responsive genes and promote cell autonomous growth (26). Activation of the P3K/Akt pathway in mice may also occur using myristolated Akt or constitutive activation of $\mathrm{p} 110 \beta$. In a murine subrenal xenograft model, activation of both AR and Akt has been noted to synergize to increase prostate tumour growth (27). Nonetheless, the exact role of this pathway in carcinogenesis in humans is uncertain. On the contrary, a recent genome wide sequencing analysis suggests that PTEN loss is a late-stage feature in the progression of prostate cancer (28).

Pre-clinical studies suggest that concomitant loss of certain proteins together with PTEN loss appear to accelerate prostate cancer progression. This has been demonstrated in mice and correlated with features of aggressiveness, such as Gleason score, in patient samples for the tumour suppressors NKX3.1, EAF2/ 


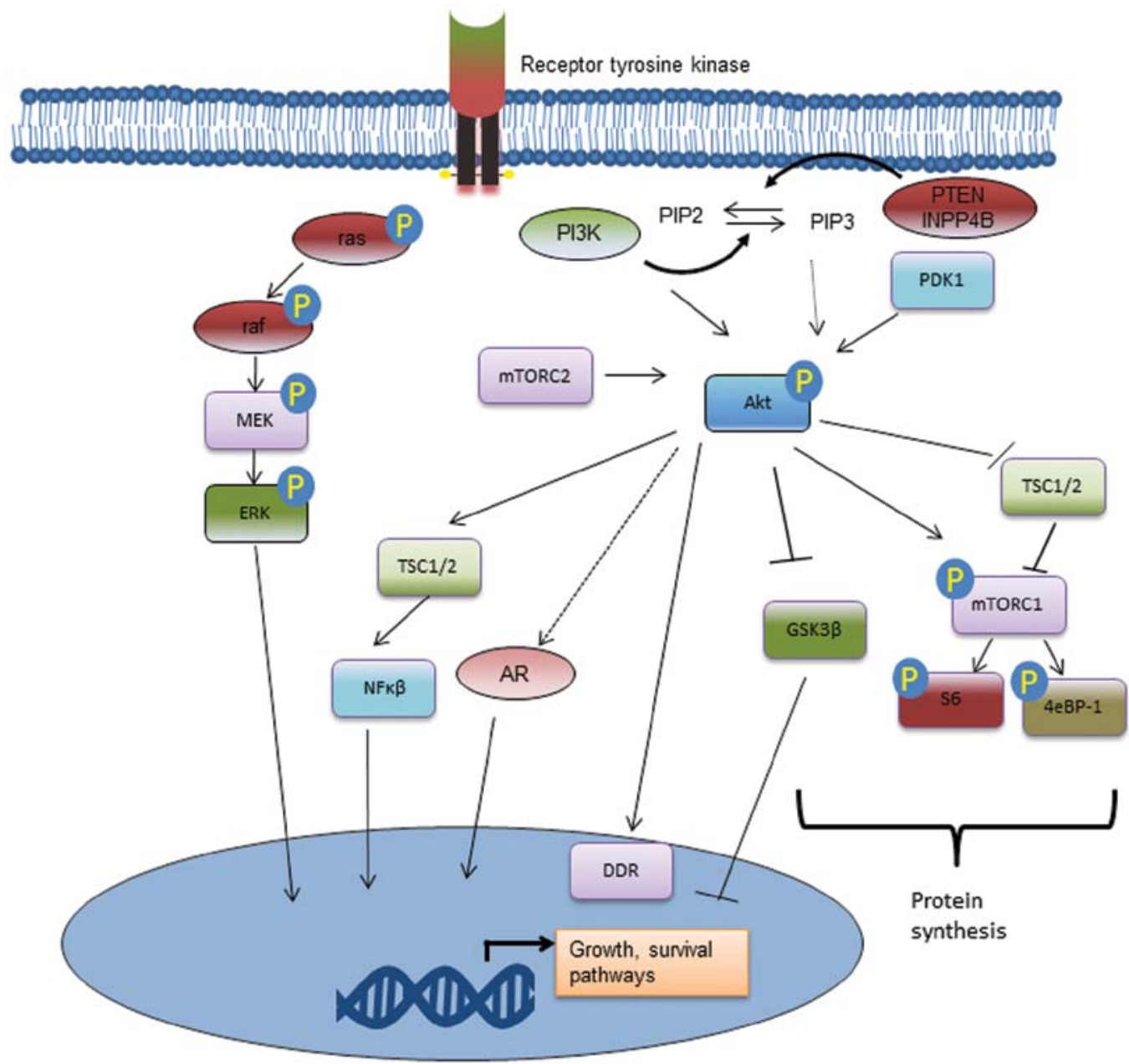

Figure 1. Schematic of some of the molecular pathways related to the PI3K/Akt pathway in prostate cancer.

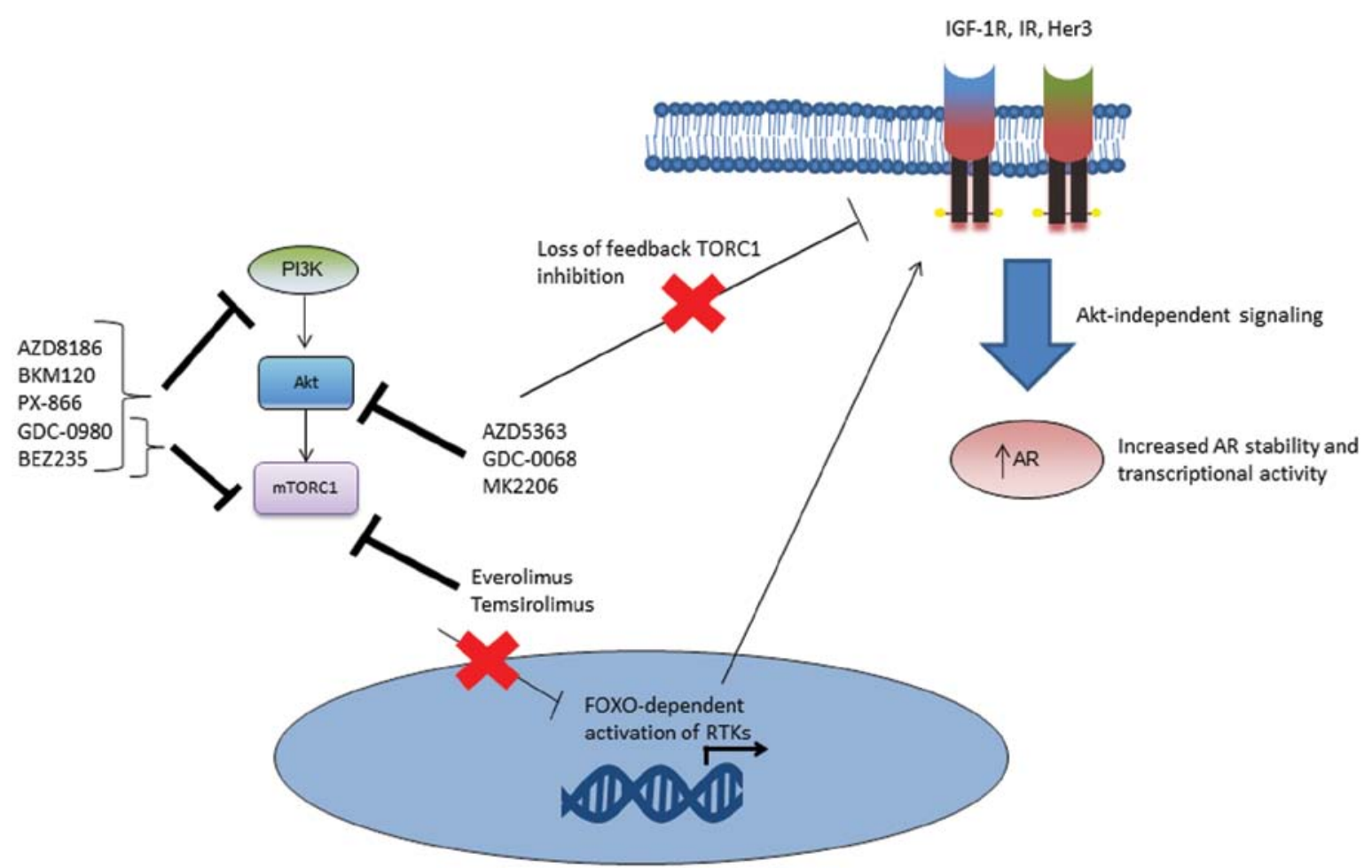

Figure 2. Schematic of selected agents targeting the PI3K/Akt pathway in being evaluated in prostate cancer with possible pathways resulting in reciprocal AR upregulation with PI3K/Akt inhibition. 
Table II. Selected pre-clinical combination studies of PI3K/Akt/mTOR inhibitors.

\begin{tabular}{|c|c|c|c|}
\hline $\begin{array}{l}\mathrm{PI} 3 \mathrm{~K} / \mathrm{Akt} / \mathrm{mTOR} \\
\text { pathway inhibitor }\end{array}$ & Additional pathway target & Selected outcomes assessed & Author (Refs.) \\
\hline $\begin{array}{l}\text { ZSTK474 } \\
\text { (Pan-PI3K inhibitor) }\end{array}$ & PSMA & $\begin{array}{l}\text { In vitro and in vivo (C4-2luc) } \\
\text { tumour growth }\end{array}$ & Baiz et al (83) \\
\hline $\begin{array}{l}\text { BEZ235 } \\
\text { (PI3K-mTOR inhibitor) }\end{array}$ & HDAC & $\begin{array}{l}\text { Attenuation of DNA damage } \\
\text { repair protein ATM }\end{array}$ & Ellis et al (13) \\
\hline $\begin{array}{l}\text { AZD5363 } \\
\text { (Akt inhibitor) }\end{array}$ & AR & $\begin{array}{l}\text { Apoptosis, proliferation, } \mathrm{LNCaP} \\
\text { tumour growth }\end{array}$ & Thomas et al (38) \\
\hline $\begin{array}{l}\text { BEZ235 } \\
\text { (PI3K/mTOR inhibitor) }\end{array}$ & Microtubules & In vitro and in vivo tumour growth & Yasumizu et al (84) \\
\hline $\begin{array}{l}\text { AZD5363 } \\
\text { (Akt inhibitor) }\end{array}$ & Autophagy & Apoptosis, tumour growth & Lamoureux et al (85) \\
\hline Akt inhibitors & Pim-1 & Apoptosis, tumour growth & Cen et al (86) \\
\hline $\begin{array}{l}\text { Rapamycin } \\
\text { (mTOR inhibitor) }\end{array}$ & MEK & In vitro and in vivo tumour growth & Kinkade et al (87) \\
\hline $\begin{array}{l}\text { Everolimus } \\
\text { (mTOR inhibitor) }\end{array}$ & $\begin{array}{l}\text { Propachlor (from } \\
\text { drug screen panel) }\end{array}$ & Authophagic cell death & Tai et al (88) \\
\hline $\begin{array}{l}\text { Perifosine } \\
\text { (Akt inhibitor) }\end{array}$ & EGFR & Apoptosis & Festuccia et al (89) \\
\hline
\end{tabular}

U19, Gata3 and Sox9 (29-33). B-raf and Stat3 activation and loss of SMAD4 and p53 signalling have also been shown in murine models to cooperate with PTEN loss to enhance prostate cancer progression (34-37). This complex network with other pathways highlights why monotherapy against the PI3K/Akt pathway may not be an optimal strategy. Table II lists different combination strategies which have been explored targeting the PI3K/Akt/ mTOR pathway in pre-clinical models of prostate cancer.

\section{PI3K/Akt and the AR pathway}

The relationship between the PI3K/Akt and AR pathways is of significant interest as a co-targeting strategy in prostate cancer (17,38). Reciprocal interactions between these pathways have been demonstrated in several pre-clinical studies $(17,39,40)$. Blockade of the AR pathway results in PHLPP-mediated Akt inactivation via a decrease in androgen regulated FKBP5 $(17,26)$. Inhibition of the PI3K/Akt pathway may result in upregulation of AR transcriptional activity via activation of membrane signalling proteins such as HER3 (Fig. 2) $(17,41)$. Direct AR phosphorylation by Akt appears to predominantly be relevant in the low-testosterone state (i.e., during androgen deprivation) $(27,42,43)$. Akt has been shown to phosphorylate the AR at Ser-213 and Ser-791, but the significance of these phosphosites is unclear (27). In vitro models suggest that Akt may regulate AR transcription (27), but that this is not by direct phosphorylation of the AR $(27,44)$.
The combination of bicalutamide and a pan-Akt inhibitor, AZD5363 have been noted in vitro and in vivo in LNCaP models to synergize to decreased tumour growth (38). Early results suggest markedly decreased in vivo tumour volumes with the use of potent pan-Akt or PI3K isoform specific inhibitors in combination with potent AR inhibitors $(45,46)$. These pre-clinical findings have supported the development of clinical trials of combination blockade of both the AR and the PI3k/Akt/mTOR pathways (Table III). Further understanding of the interactions between these pathways in pre-clinical models may aid in design of future clinical trials.

\section{PI3K/Akt pathway as a biomarker in prostate cancer}

With the aggressive oncogenic characteristics of the PI3K/Akt pathway, there has been significant interest to use this pathway as a biomarker to differentiate more significant, lethal prostate cancer from more indolent disease. While it does appear from the current data that this pathway does provide prognostic information, it is unclear that it provides any significant improvement over currently used clinical and pathologic markers. However, there is ongoing interest to use this pathway as a predictive biomarker for newer targeted agents of this pathway.

The challenges of using this pathway as a biomarker relate in large part to the complexity of the biology in advanced prostate cancer and tumour heterogeneity. Firstly, there is a large diversity of mutations and genomic alterations which may 
Table III. PI3K/Akt inhibitors in current clinical evaluation for prostate cancer.

\begin{tabular}{|c|c|c|c|c|c|}
\hline Drug & Inhibitors & Phase & Regimen & Population & Trial registry no. ${ }^{\mathrm{b}}$ \\
\hline $\begin{array}{l}\text { AZD8186 } \\
\text { (AstraZeneca) }\end{array}$ & PI3K $\beta$ and $\delta$ inhibitor & I & Monotherapy & CRPC & NCT01884285 \\
\hline $\begin{array}{l}\text { BKM120 } \\
\text { (Novartis) }\end{array}$ & Pan-PI3K inhibitor & $\begin{array}{l}\text { I } \\
\text { I } \\
\text { II }\end{array}$ & $\begin{array}{l}+ \text { abiraterone acetate } \\
+ \text { abiraterone acetate } \\
\text { Monotherapy }\end{array}$ & $\begin{array}{l}\text { Post-abiraterone CRPC } \\
\text { mCRPC } \\
\text { Post-chemo }\end{array}$ & $\begin{array}{l}\text { NCT01634061 } \\
\text { NCT01741753 } \\
\text { NCT01385293 }\end{array}$ \\
\hline $\begin{array}{l}\text { PX-866 } \\
\text { (Oncothyreon) }\end{array}$ & Pan-PI3K inhibitor & II & Monotherapy & mCRPC post ADT & NCT01331083 \\
\hline $\begin{array}{l}\text { BEZ235 } \\
\text { (Novartis) }\end{array}$ & PI3K/mTOR inhibitor & $\mathrm{I}$ & + abiraterone acetate & Post-abiraterone CRPC & NCT01634061 \\
\hline $\begin{array}{l}\text { GDC-0980 } \\
\text { (Genetech) }\end{array}$ & PI3K/mTOR inhibitor & $\mathrm{I} / \mathrm{II}$ & + abiraterone acetate & Post-docetaxel & $\begin{array}{l}\text { NCT01485861 } \\
2011-004126-10\end{array}$ \\
\hline $\begin{array}{l}\text { AZD5363 } \\
\text { (AstraZeneca) }\end{array}$ & Akt inhibitor & $\begin{array}{c}\mathrm{I} \\
\mathrm{II} \\
\mathrm{I} / \mathrm{II}\end{array}$ & $\begin{array}{l}\text { Monotherapy } \\
+ \text { enzalutamide } \\
\text { + docetaxel }\end{array}$ & $\begin{array}{l}\mathrm{mCRPC} \\
\mathrm{mCRPC} \\
\mathrm{mCRPC}\end{array}$ & $\begin{array}{l}\text { NCT01692262 } \\
\text { 2013-004091-34 } \\
\text { NCT02121639 }\end{array}$ \\
\hline $\begin{array}{l}\text { GDC-0068 } \\
\text { (Genetech) }\end{array}$ & Akt inhibitor & $\mathrm{I} / \mathrm{II}$ & + abiraterone acetate & Post-docetaxel & $\begin{array}{l}\text { NCT01485861 } \\
2011-004126-10\end{array}$ \\
\hline $\begin{array}{l}\text { MK2206 } \\
\text { (Merck) }\end{array}$ & Akt inhibitor & II & + bicaluatmide & $\begin{array}{l}\text { Biochemical failure } \\
\text { after primary therapy }\end{array}$ & NCT01251861 \\
\hline $\begin{array}{l}\text { Everolimus } \\
\text { (Novartis) }\end{array}$ & mTORC1 inhibitor & $\begin{array}{c}\mathrm{II} \\
\mathrm{I} / \mathrm{II}\end{array}$ & $\begin{array}{l}\text { + pasireotide (somatostatin) } \\
\text { + docetaxel, bevacizumab } \\
\text { (VEGF inhibitor) }\end{array}$ & $\begin{array}{l}\text { Chemo-naïve CRPC } \\
\text { mCRPC }\end{array}$ & $\begin{array}{l}\text { NCT01313559 } \\
\text { NCT00574769 }\end{array}$ \\
\hline & & II & $\begin{array}{l}\text { + carboplatin, everolimus, } \\
\text { and prednisone } \\
+ \text { bicalutamide }\end{array}$ & $\begin{array}{l}\text { Recurrent or mCRPC } \\
\text { post ADT }\end{array}$ & NCT00814788 \\
\hline $\begin{array}{l}\text { Temsirolimus } \\
\text { (Wyeth) }\end{array}$ & mTORC1 inhibitor & $\begin{array}{c}\mathrm{I} / \mathrm{II} \\
\mathrm{I} \\
\mathrm{II} \\
\mathrm{I} / \mathrm{II}\end{array}$ & $\begin{array}{l}\text { + bevacizumab } \\
\text { + vorinostat } \\
\text { Monotherapy } \\
\text { + docetaxel }\end{array}$ & $\begin{array}{l}\text { Post-docetaxel mCRPC } \\
\text { Post-docetaxel mCRPC } \\
\text { CRPC } \\
\text { CRPC }\end{array}$ & $\begin{array}{l}\text { NCT01083368 } \\
\text { NCT01174199 } \\
2011-002087-24 \\
\text { NCT01206036 } \\
2010-018370-21 \\
\text { NCT01026623 }\end{array}$ \\
\hline
\end{tabular}

${ }^{a}$ Both abiraterone acetate and docetaxel are given in combination with low dose prednisone. ${ }^{\mathrm{b}}$ ClinicalTrials.gov number and/or EudraCT number.

activate this pathway, making any single marker less sensitive. Further, the context of this pathway in prostate cancer differs from other malignancies where this pathway also plays an important role. For example, while activating PI3KCA mutations are relatively common among advanced malignancies, it does not appear to be as common in prostate cancer (47). Factors in the tumour microenvironment can influence signalling of this pathway, which is downstream of various cell surface receptors. Therefore, both tumour and patient heterogeneity contribute to a complexity making biomarker evaluation and validation more challenging. For example, in circulating tumour cells PTEN allelic loss has significant heterogeneity when analyzed by fluorescent in situ hybridization (48). Further, on immunohistochemistry, analysis of downstream targets does not clearly correlate in patient samples with the phosphorylation of Akt. In one study, phosphorylation of downstream GSK3 $\beta$ and a forkhead transcription factor was noted in only 29 and $40 \%$ of cases, respectively, in localized prostate cancer samples with phospho-Akt (49). Finally, technical variation, antibody limitations, tissue acquisition and processing also present challenges to use of this pathway as a clinical biomarker. 
It is estimated that genomic PTEN alterations are found in $9-45 \%$ of high grade prostate intra-epithelial neoplasia (HG-PIN), increase to $20-60 \%$ in localized prostate cancer, and are altered in up to $100 \%$ of cases of metastatic prostate cancer $(47,50)$. Homozygous deletion of PTEN is linked with CRPC (51). Further, PTEN is the most common gene with loss of heterozygosity in circulating tumour cells CTCs (52). Similarly, mutations in the PI3K pathway occur more frequently in metastatic tissue compared to primary tumours. In the Taylor et al dataset, mutations in the PI3K regulatory genes PIK3R1, PIK3R3 and PIK3CS occur at a frequency of 22,2 and $6 \%$ in primary tumours, respectively. In metastatic tissues, the frequency increases to 58,16 and $16 \%$, respectively (47). Mutations in PIK3CA catalytic gene of PI3K are known to be activating to the pathway and also may predict response to therapy with PI3K inhibitors, though they are not highly prevalent in prostate cancer (53). Mutations in the regulatory phosphatase PHLPP gene can also result in activation of the Akt pathway, occurring at 11 and $37 \%$ in primary and metastatic tumours, respectively (47).

On immunohistochemistry, both PTEN status and phosphoAkt are the most commonly investigated biomarkers. Akt can be phosphorylated at Thr308 and Ser473; it appears that both sites are usually phosphorylated in the active state. It does appear that Akt staining is specific to tumour cells, without any staining in adjacent stromal tissue (49). Not surprisingly given the molecular features of the activated PI3K/Akt pathway, the loss of PTEN staining in localized prostate cancer samples correlates with higher Gleason score and pathologic stage $(54,55)$ as well as an increased risk of positive lymph nodes (56). PTEN protein loss on immunohistochemistry of the primary tumour has also been associated with shorter time to biochemical recurrence post radical prostatectomy, but not consistently (57). Levels of phospho-Akt increase with higher Gleason grade $(58,59)$ and are associated with poorer survival in CRPC (60). However, it is unclear whether they hold any prognostic significance in low and intermediate grade disease (Gleason score 6-7) (59). Levels of phospho-Akt also predict for biochemical recurrence post radical prostatectomy, with improved prediction when used in combination with PTEN protein loss (61). Loss of INPP4B has been noted to be a good marker of aggressive breast cancer (62), but has not been explored in prostate cancer. Another area which remains to be more fully explored is the cellular localization of phospho-Akt. It is unclear whether increased nuclear staining improves prognostication, as suggested by one study which found that greater nuclear phospho-Akt staining was associated with higher Gleason grade (63).

In addition to the above mentioned studies on the use of PTEN, phospho-Akt or other related proteins as prognostic biomarkers, there is significant interest into the use of predictive biomarkers for PI3K/Akt targeting agents. Only a few studies to date have investigated predictive biomakers, but this area is expected to increase as more inhibitors of this pathway enter clinical evaluation. In unselected men with CRPC, PTEN status on immunohistochemistry did not predict response to everolimus (64). Activating mutations in mTOR were found in one patient with an excellent response to combination everolimus and pazopanib (65). Similar anecdotal responses to AZD5363, a pan-Akt inhibitor has been reported to be associated with genetic alterations, but not yet in prostate cancer patients (66). Prospected clinical investigation and validation is ongoing to identify and evaluate appropriate predictive biomarkers in patients for response to PI3K/Akt inhibitor therapy in prostate cancer patients.

\section{Clinical studies of PI3K/Akt/mTOR inhibitors in prostate cancer}

Several novel PI3K/Akt/mTOR pathway inhibitors are in clinical development (Table III) for advanced prostate cancer. Two studies have evaluated monotherapy with the Akt inhibitor perifosine in prostate cancer. Perifosine is an alkylphospholid with Akt inhibitor properties. Akylphospholipids are known to accumulate in cell membranes, but the exact reason for the anticancer activity is unclear, but this is presumed due to its capacity to inhibit the Akt pathway. A phase II trial of perifosine monotherapy in 25 patients with biochemical recurrence after primary therapy did not alter PSA doubling time and was ended early for lack of response (67). No significant toxicities were reported in this relatively healthy population. A second trial in 19 patients with metastatic prostate cancer also demonstrated minimal benefit (68). The median time to progression was 4 weeks, with only 4 patients having stable disease beyond 12 weeks. A recent phase III trial with perifosine in colon cancer has also found no therapeutic benefit (69).

The novel agents now in development (Table III) differ significantly from perifosine's mechanism of action and limited side effects. Most are small molecule reversible inhibitors of the catalytic function of PI3K, Akt, and/or mTOR. The common adverse effects of PI3k/Akt inhibitors reported to date include insulin resistance, hyperglycemia, nausea and mood alterations. PI3K inhibitors include non-specific and isoform-specific inhibitors. The three isoforms (p110 $\alpha, \beta$, and $\delta$ ) of class IA PI3K may play relatively different roles in the progression of prostate cancer (7). Isoform-specific inhibitors in prostate cancer aim to inhibit only the PI3K $\beta$ and $\delta$ isoforms to decrease insulin resistance and hyperglycemia associated with PI3K $\alpha$ inhibition (70).

BKM120 is an oral pan-PI3K inhibitor with reported clinical data in advanced solid tumours, including prostate cancer (71). Among 31 patients in the phase I trial, one had a partial response and $12(52 \%)$ had stable disease. Treatmentrelated adverse events include rash, hyperglycemia, diarrhea, anorexia, mood alteration, nausea and fatigue. Reversible neuropsychiatric adverse events may be due to BKM120 crossing the blood-brain barrier and inhibiting PI3K/Akt/mTOR signalling modulating neurotransmitter concentrations. Similarly, results with the oral pan-Akt inhibitor AZD5363 showed two partial responses out of 92 patients in two phase I trials (66). Notably, both patients had mutations in Akt1 or PI3KCA, suggesting mutations in these genes may be predictive of response.

Results to date with inhibition of downstream TORC1 or TORC2 in prostate cancer have been disappointing. Rapalogs such as everolimus, temsirolimus, and ridaforolimus have had poor results as single agents in prostate cancer clinical trials $(64,72)$. This may be due in part to TORC2 mediated feedback on Akt (10). Dual TORC1/TORC2 inhibition has demonstrated improved inhibition of downstream effectors such as the eIF-4E protein translation complex not seen with mTORC1 inhibition (73). Dual mTORC1/mTORC2 inhibi- 
tors have entered clinical testing for advanced solid tumours, including prostate cancer (74).

\section{Combination targeting in prostate cancer}

From pre-clinical data to date, as well as the failure of prior monotherapy trials, it appears that targeting of the PI3K/Akt pathway in prostate cancer is optimally done in combination with other agents. While monotherapy with newer agents may have some activity, the abundance of cross-talk with other pathways seen in pre-clinical studies suggests that resistance will develop as other pathways are reciprocally upregulated. In breast cancer, the combination of the aromatase inhibitor targeting the estrogen receptor with everolimus targeting mTOR demonstrated significant synergy (75). In an analogous manner in prostate cancer, rationale combination therapy may significantly improve clinical response rates and reduce the development of resistance.

Combination therapy with PI3K/Akt/mTOR inhibitors in prostate cancer can be conceptualized as vertical blockade, with inhibition of multiple nodes in the PI3K/Akt pathway or horizontal blockade, with inhibition of the PI3K/Akt pathway together with other parallel pathways. For example, pre-clinical work in transgenic mice suggests that dual targeting of the Akt and mTOR signalling (i.e., vertical blockade) has significantly more activity compared to either monotherapy (76). Dual PI3K/ mTOR blockade with one molecule is facilitated by similarities of the PI3K and mTOR catalytic sites. Similarly, effective combinations of Akt or mTOR inhibition with AR blockade has been noted in other pre-clinical studies $(17,38,77)$. Combination of Akt inhibition with receptor tyrosine kinases is another horizontal blockade strategy with good pre-clinical data (10).

Many of the ongoing clinical trials are evaluating a $\mathrm{PI} 3 \mathrm{~K} / \mathrm{Akt}$ inhibitor in combination with an AR pathway inhibitor (Table III). A limited number of trials targeting both pathways have been reported in prostate cancer. A study in 36 patients with CRPC of the mTOR inhibitor everolimus in combination with bicalutamide has been reported (78). This study did not show any benefit for the combination, though it was well tolerated. Reasons for the lack of benefit could include a possible partial agonist effect of bicalutamide, lack of effective AR inhibition with bicalutamide as well as the activation of upstream Akt as a result of mTOR inhibition. However, another phase I/ II trial found that of 13 patients treated with bicalutamide and everolimus, 9 had a partial response, one an unconfirmed partial response and 3 had stable disease. Of the 5 patients treated with placebo + bicalutamide, 1 had partial response, one unconfirmed partial response, 2 stable disease and 1 had disease progression. The mean time to relapse was 220 days for the everolimus + bicalutamide vs 109 days for placebo + bicalutamide (79). Very early results of the combination of BKM120 with abiraterone and prednisone are also promising (80).

One putative benefit of combination therapy is decreased toxicity while maintaining therapeutic efficacy. However, this has yet to be consistently observed in clinical trials in patients. Increased toxicity has been noted in some early studies to date when using combination therapy $(81,82)$. In a clinical trial of 11 patients with CRPC treated with ridaforolimus and bicalutamide, 3 had dose-limiting toxicity, including hyperglycemia and stomatitis. It is anticipated that continued experience with these newer PI3K inhibitors will result in better dosing schedules to minimize adverse effects, while maintaining therapeutic efficacy.

\section{Conclusion}

Activation of the PI3K/Akt pathway clearly plays a major role in the aggressive nature of many prostate cancers. With the use of newer AR pathway inhibitors and combination therapy, this non-androgen receptor pathway may become increasingly relevant as more patients develop non-AR driven tumours. Clinical trials are now assessing the efficacy of targeting this pathway in CRPC. An improved understanding of the biology and relevant biomarkers of this pathway in prostate cancer will be important to understand which patients will benefit from PI3K/Akt/ mTOR inhibitors and at what point in the disease course they should be given. The use of combination therapy has potential to substantially improve the outcome of patients, but needs to be balanced against toxicities, particularly if combination therapies are utilized earlier in the course of disease.

\section{References}

1. 'What are the key statistics about prostate cancer?' American Cancer Society. http://www.cancer.org/cancer/prostatecancer/ detailedguide/prostate-cancer-key-statistics. Accessed April 27, 2014.

2. Scher HI, Fizazi K, Saad F, et al: Increased survival with enzalutamide in prostate cancer after chemotherapy. N Engl J Med 367: 1187-1197, 2012.

3. Ryan CJ, Smith MR, de Bono JS, et al: Abiraterone in metastatic prostate cancer without previous chemotherapy. N Engl J Med 368: 138-148, 2013.

4. Donahue TR, Tran LM, Hill R, et al: Integrative survival-based molecular profiling of human pancreatic cancer. Clin Cancer Res 18: 1352-1363, 2012.

5. Martini M, Ciraolo E, Gulluni F and Hirsch E: Targeting PI3K in cancer: any good news? Front Oncol 3: 108, 2013.

6. Jia S, Liu Z, Zhang S, et al: Essential roles of PI(3)K-p110beta in cell growth, metabolism and tumorigenesis. Nature 454: 776-779, 2008.

7. Jiang X, Chen S, Asara JM and Balk SP: Phosphoinositide 3-kinase pathway activation in phosphate and tensin homolog (PTEN)-deficient prostate cancer cells is independent of receptor tyrosine kinases and mediated by the p110beta and p110delta catalytic subunits. J Biol Chem 285: 14980-14989, 2010.

8. Drake JM, Graham NA, Lee JK, et al: Metastatic castrationresistant prostate cancer reveals intrapatient similarity and interpatient heterogeneity of therapeutic kinase targets. Proc Natl Acad Sci USA 110: E4762-E4769, 2013.

9. Kremer CL, Klein RR, Mendelson J, et al: Expression of mTOR signaling pathway markers in prostate cancer progression. Prostate 66: 1203-1212, 2006.

10. Bitting RL and Armstrong AJ: Targeting the PI3K/Akt/mTOR pathway in castration-resistant prostate cancer. Endocr Relat Cancer 20: R83-R99, 2013.

11. Dibble CC, Asara JM and Manning BD: Characterization of Rictor phosphorylation sites reveals direct regulation of mTOR complex 2 by S6K1. Mol Cell Biol 29: 5657-5670, 2009.

12. Cantley LC: The phosphoinositide 3-kinase pathway. Science 296: 1655-1657, 2002.

13. Ellis L, Ku SY, Ramakrishnan S, et al: Combinatorial antitumor effect of HDAC and the PI3K-Akt-mTOR pathway inhibition in a Pten defecient model of prostate cancer. Oncotarget 4: 2225-2236, 2013.

14. Yue S, Li J, Lee SY, et al: Cholesteryl ester accumulation induced by PTEN loss and PI3K/AKT activation underlies human prostate cancer aggressiveness. Cell Metab 19: 393-406, 2014.

15. Muniyan S, Ingersoll MA, Batra SK and Lin MF: Cellular prostatic acid phosphatase, a PTEN-functional homologue in prostate epithelia, functions as a prostate-specific tumor suppressor. Biochim Biophys Acta: pii: S0304-419X(14)00042-0. Apr 18, 2014 (Epub ahead of print). doi: 10.1016/j.bbcan.2014.04.006. 
16. Hodgson MC, Shao LJ, Frolov A, et al: Decreased expression and androgen regulation of the tumor suppressor gene INPP4B in prostate cancer. Cancer Res 71: 572-582, 2011.

17. Carver BS, Chapinski C, Wongvipat J, et al: Reciprocal feedback regulation of PI3K and androgen receptor signaling in PTENdeficient prostate cancer. Cancer Cell 19: 575-586, 2011.

18. Phin S, Moore MW and Cotter PD: Genomic rearrangements of in prostate cancer. Front Oncol 3: 240, 2013.

19. Fata JE, Debnath S, Jenkins EC Jr and Fournier MV: Nongenomic mechanisms of PTEN regulation. Int J Cell Biol 2012: 379685, 2012.

20. Ahmad I, Patel R, Singh LB, et al: HER2 overcomes PTEN (loss)-induced senescence to cause aggressive prostate cancer. Proc Natl Acad Sci USA 108: 16392-16397, 2011.

21. Zu K, Martin NE, Fiorentino M, et al: Protein expression of PTEN, insulin-like growth factor I receptor (IGF-IR), and lethal prostate cancer: a prospective study. Cancer Epidemiol Biomarkers Prev 22: 1984-1993, 2013.

22. Nacerddine K, Beaudry JB, Ginjala V, et al: Akt-mediated phosphorylation of Bmil modulates its oncogenic potential, E3 ligase activity, and DNA damage repair activity in mouse prostate cancer. J Clin Invest 122: 1920-1932, 2012.

23. Dubrovska A, Kim S, Salamone RJ, et al: The role of PTEN/ $\mathrm{Akt} / \mathrm{PI} 3 \mathrm{~K}$ signaling in the maintenance and viability of prostate cancer stem-like cell populations. Proc Natl Acad Sci USA 106: 268-273, 2009.

24. Wang S, Gao J, Lei Q, et al: Prostate-specific deletion of the murine Pten tumor suppressor gene leads to metastatic prostate cancer. Cancer Cell 4: 209-221, 2003.

25. Blando J, Portis M, Benavides F, et al: PTEN deficiency is fully penetrant for prostate adenocarcinoma in C57BL/6 mice via mTOR-dependent growth. Am J Pathol 174: 1869-1879, 2009.

26. Mulholland DJ, Tran LM, Li Y, et al: Cell autonomous role of PTEN in regulating castration-resistant prostate cancer growth. Cancer Cell 19: 792-804, 2011.

27. Xin L, Teitell MA, Lawson DA, Kwon A, Mellinghoff IK and Witte ON: Progression of prostate cancer by synergy of AKT with genotropic and nongenotropic actions of the androgen receptor. Proc Natl Acad Sci USA 103: 7789-7794, 2006.

28. Baca Sylvan C, Prandi D, Lawrence Michael S, et al: Punctuated evolution of prostate cancer genomes. Cell 153: 666-677, 2013.

29. Nguyen AH, Tremblay M, Haigh K, et al: Gata3 antagonizes cancer progression in Pten-deficient prostates. Hum Mol Genet 22: 2400-2410, 2013.

30. Ai J, Pascal LE, O'Malley KJ, et al: Concomitant loss of EAF2/U19 and Pten synergistically promotes prostate carcinogenesis in the mouse model. Oncogene 33: 2286-2294, 2014.

31. Thomsen MK, Ambroisine L, Wynn S, et al: SOX9 elevation in the prostate promotes proliferation and cooperates with PTEN loss to drive tumor formation. Cancer Res 70: 979-987, 2010

32. Kim MJ, Cardiff RD, Desai N, et al: Cooperativity of Nkx3.1 and Pten loss of function in a mouse model of prostate carcinogenesis. Proc Natl Acad Sci USA 99: 2884-2889, 2002.

33. Song H, Zhang B, Watson MA, Humphrey PA, Lim H and Milbrandt J: Loss of Nkx3.1 leads to the activation of discrete downstream target genes during prostate tumorigenesis. Oncogene 28: 3307-3319, 2009.

34. Chen Z, Trotman LC, Shaffer D, et al: Crucial role of p53-dependent cellular senescence in suppression of Pten-deficient tumorigenesis. Nature 436: 725-730, 2005.

35. Blando JM, Carbajal S, Abel E, et al: Cooperation between Stat3 and Akt signaling leads to prostate tumor development in transgenic mice. Neoplasia 13: 254-265, 2011.

36. Ding Z, Wu CJ, Chu GC, et al: SMAD4-dependent barrier constrains prostate cancer growth and metastatic progression. Nature 470: 269-273, 2011.

37. Wang J, Kobayashi T, Floc'h N, et al: B-Raf activation cooperates with PTEN loss to drive c-Myc expression in advanced prostate cancer. Cancer Res 72: 4765-4776, 2012.

38. Thomas C, Lamoureux F, Crafter C, et al: Synergistic targeting of PI3K/AKT pathway and androgen receptor axis significantly delays castration-resistant prostate cancer progression in vivo. Mol Cancer Ther 12: 2342-2355, 2013.

39. Wang Y, Kreisberg JI and Ghosh PM: Cross-talk between the androgen receptor and the phosphatidylinositol 3-kinase/Akt pathway in prostate cancer. Curr Cancer Drug Targets 7: 591-604, 2007.

40. Kaarbo M, Mikkelsen OL, Malerod L, et al: PI3K-AKT-mTOR pathway is dominant over androgen receptor signaling in prostate cancer cells. Cell Oncol 32: 11-27, 2010.
41. Chandarlapaty S, Sawai A, Scaltriti M, et al: AKT inhibition relieves feedback suppression of receptor tyrosine kinase expression and activity. Cancer Cell 19: 58-71, 2011.

42. Wen Y, Hu MCT, Makino K, et al: HER-2/neu promotes androgen-independent survival and growth of prostate cancer cells through the Akt pathway. Cancer Res 60: 6841-6845, 2000.

43. Manin M, Baron S, Goossens K, et al: Androgen receptor expression is regulated by the phosphoinositide 3-kinase/Akt pathway in normal and tumoral epithelial cells. Biochem J 366: 729-736, 2002.

44. Nan B, Snabboon T, Unni E, X-J Y, Whang Y and Marcelli M: The PTEN tumor suppressor is a negative modulator of androgen receptor transcriptional activity. J Mol Endocrinol 31: 169-183, 2003.

45. Schwartz S, Carver B, Wongvipat J, et al: The antitumor effects of PI3K beta inhibitors in PTEN negative prostate cancer are enhanced by inhibition of reactivated PI3K alpha signaling. Proc 105th Annual Meeting Amer Assoc Cancer Res, abs. 4774, 2014.

46. Toren P, Kim S, Gleave M and Zoubeidi A: Combined targeting of PI3K/Akt and AR pathway with AZD5363 and enzalutamide induces anticancer activity in preclinical models of prostate cancer. J Urol 189 (Suppl 14): e403, 2013.

47. Taylor BS, Schultz N, Hieronymus $\mathrm{H}$, et al: Integrative genomic profiling of human prostate cancer. Cancer Cell 18: 11-22, 2010.

48. Attard G, Swennenhuis JF, Olmos D, et al: Characterization of ERG, AR and PTEN gene status in circulating tumor cells from patients with castration-resistant prostate cancer. Cancer Res 69: 2912-2918, 2009.

49. Jendrossek V, Henkel M, Hennenlotter J, et al: Analysis of complex protein kinase B signalling pathways in human prostate cancer samples. BJU Int 102: 371-382, 2008.

50. Jia S, Gao X, Lee SH, et al: Opposing effects of androgen deprivation and targeted therapy on prostate cancer prevention. Cancer Discov 3: 44-51, 2013.

51. Sircar K, Yoshimoto M, Monzon FA, et al: PTEN genomic deletion is associated with p-Akt and AR signalling in poorer outcome, hormone refractory prostate cancer. J Pathol 218: 505-513, 2009.

52. Schmidt H, DeAngelis G, Eltze E, Gockel I, Semjonow A and Brandt B: Asynchronous growth of prostate cancer is reflected by circulating tumor cells delivered from distinct, even small foci, harboring loss of heterozygosity of the PTEN gene. Cancer Res 66: 8959-8965, 2006.

53. Janku F, Tsimberidou AM, Garrido-Laguna I, et al: PIK3CA mutations in patients with advanced cancers treated with PI3K/ AKT/mTOR axis inhibitors. Mol Cancer Ther 10: 558-565, 2011.

54. McMenamin ME, Soung P, Perera S, Kaplan I, Loda M and Sellers WR: Loss of PTEN expression in paraffin-embedded primary prostate cancer correlates with high Gleason score and advanced stage. Cancer Res 59: 4291-4296, 1999.

55. Dreher T, Zentgraf $\mathrm{H}$, Abel U, et al: Reduction of PTEN and p27kip1 expression correlates with tumor grade in prostate cancer. Analysis in radical prostatectomy specimens and needle biopsies. Virchows Arch 444: 509-517, 2004.

56. Schmitz M, Grignard G, Margue C, et al: Complete loss of PTEN expression as a possible early prognostic marker for prostate cancer metastasis. Int J Cancer 120: 1284-1292, 2007.

57. Koumakpayi IH, Le Page C, Mes-Masson AM and Saad F: Hierarchical clustering of immunohistochemical analysis of the activated ErbB/PI3K/Akt/NF-kappaB signalling pathway and prognostic significance in prostate cancer. Br J Cancer 102: $1163-1173,2010$

58. Malik SN, Brattain M, Ghosh PM, et al: Immunohistochemical demonstration of phospho-Akt in high Gleason grade prostate cancer. Clin Cancer Res 8: 1168-1171,2002.

59. Hammarsten P, Cipriano M, Josefsson A, et al: Phospho-Akt immunoreactivity in prostate cancer: relationship to disease severity and outcome, Ki67 and phosphorylated EGFR expression. PLoS One 7: e47994, 2012.

60. McCall P, Gemmell LK, Mukherjee R, Bartlett JM and Edwards J: Phosphorylation of the androgen receptor is associated with reduced survival in hormone-refractory prostate cancer patients. Br J Cancer 98: 1094-1101, 2008.

61. Bedolla R, Prihoda TJ, Kreisberg JI, et al: Determining risk of biochemical recurrence in prostate cancer by immunohistochemical detection of PTEN expression and Akt activation. Clin Cancer Res 13: 3860-3867, 2007. 
62. Won JR, Gao D, Chow C, et al: A survey of immunohistochemical biomarkers for basal-like breast cancer against a gene expression profile gold standard. Mod Pathol 26: 1438-1450, 2013.

63. Van de Sande T, Roskams T, Lerut E, et al: High-level expression of fatty acid synthase in human prostate cancer tissues is linked to activation and nuclear localization of Akt/PKB. J Pathol 206 : 214-219, 2005

64. Templeton AJ, Dutoit V, Cathomas R, et al: Phase 2 trial of single-agent everolimus in chemotherapy-naive patients with castration-resistant prostate cancer (SAKK 08/08). Eur Urol 64 : 150-158, 2013.

65. Wagle N, Grabiner BC, Van Allen EM, et al: Activating mTOR mutations in a patient with an extraordinary response on a phase I trial of everolimus and pazopanib. Cancer Discov 4: 546-553, 2014.

66. Banerji U: Results of two phase 1 multicenter trials of AZD5363, an inhibitor of AKT1, 2 and 3: biomarker and early clinical evaluation in Western and Japanese patients with advanced solid tumors. 2013. Proc Annual Meeting Amer Assoc Cancer Res (abstract LB-66), 2013.

67. Chee KG, Longmate J, Quinn DI, et al: The AKT inhibitor perifosine in biochemically recurrent prostate cancer: a phase II California/Pittsburgh cancer consortium trial. Clin Genitourin Cancer 5: 433-437, 2007.

68. Posadas EM, Gulley J, Arlen PM, et al: A phase II study of perifosine in androgen independent prostate cancer. Cancer Biol Ther 4: 1133-1137, 2005.

69. Bendell JC, Ervin TE, Senzer N, et al: Results of the X-PECT study: a phase III randomized double-blind, placebo-controlled study of perifosine plus capecitabine (P-CAP) versus placebo plus capecitabine (CAP) in patients (pts) with refractory metastatic colorectal cancer (mCRC). J Clin Oncol 30: LBA3501, 2012.

70. Busaidy NL, Farooki A, Dowlati A, et al: Management of metabolic effects associated with anticancer agents targeting the PI3K-Akt-mTOR pathway. J Clin Oncol 30: 2919-2928, 2012.

71. Bendell JC, Rodon J, Burris HA, et al: Phase I dose-escalation and -expansion study of buparlisib (BKM120), an oral pan-class I PI3K inhibitor, in patients with advanced solid tumors. J Clin Oncol 30: 282-290, 2012.

72. Amato RJ, Wilding G, Bubley G, Loewy J, Haluska F and Gross ME: Safety and preliminary efficacy analysis of the mTOR inhibitor ridaforolimus in patients with taxane-treated, castration-resistant prostate cancer. Clin Genitourin Cancer 10: 232-238, 2012

73. Hsieh AC, Liu Y, Edlind MP, et al: The translational landscape of mTOR signalling steers cancer initiation and metastasis. Nature 485: 55-61, 2012 .

74. Mateo J, Schoffski P, Olmos D, et al: Abstract B187: Pharmacodynamics of OSI-027, a dual mTORC $1 / \mathrm{mTORC} 2$ inhibitor, in tumor and surrogate tissues: Results from the expansion phase of a first-in-man study. Mol Cancer Ther 12: B187, 2013.

75. Baselga J, Campone M, Piccart M, et al: Everolimus in postmenopausal hormone-receptor-positive advanced breast cancer N Engl J Med 366: 520-529, 2012.
76. Floc'h N, Kinkade CW, Kobayashi T, et al: Dual targeting of the Akt/mTOR signaling pathway inhibits castration-resistant prostate cancer in a genetically engineered mouse model. Cancer Res 72: 4483-4493, 2012.

77. Squillace RM, Miller D, Wardwell SD, Wang F, Clackson T and Rivera VM: Synergistic activity of the mTOR inhibitor ridaforolimus and the antiandrogen bicalutamide in prostate cancer models. Int J Oncol 41: 425-432, 2012.

78. Nakabayashi M, Werner L, Courtney KD, et al: Phase II trial of RAD001 and bicalutamide for castration-resistant prostate cancer. BJU Int 110: 1729-1735, 2012.

79. Pan C, Robles D, D'Abronzo L, et al: Synergistic effects of everolimus and bicalutamide in castration-resistant prostate cancer: results from a phase I/II clinical trial. Cancer Res 72 : 5750, 2012

80. Patnaik A, Loda M, Kung J, et al: A phase Ib study of BKM120 combined with abiraterone acetate for castrate-resistant, metastatic prostate cancer. Proc 105th Annual Meeting Amer Assoc Cancer Res, abs. CT418, 2014.

81. Janne PA, Cohen RB, Laird AD, et al: Phase I safety and pharmacokinetic study of the PI3K/mTOR inhibitor SAR245409 (XL765) in combination with erlotinib in patients with advanced solid tumors. J Thorac Oncol 9: 316-323, 2014.

82. Meulenbeld HJ, de Bono JS, Tagawa ST, et al: Tolerability, safety and pharmacokinetics of ridaforolimus in combination with bicalutamide in patients with asymptomatic, metastatic castration-resistant prostate cancer (CRPC). Cancer Chemother Pharmacol 72: 909-916, 2013

83. Baiz D, Hassan S, Choi YA, et al: Combination of the PI3K inhibitor ZSTK474 with a PSMA-targeted immunotoxin accelerates apoptosis and regression of prostate cancer. Neoplasia 15 1172-1183, 2013.

84. Yasumizu Y, Miyajima A, Kosaka T, Miyazaki Y, Kikuchi E and Oya M: Dual PI3K/mTOR inhibitor NVP-BEZ235 sensitizes docetaxel in castration resistant prostate cancer. J Urol 191: 227-234, 2014.

85. Lamoureux F, Thomas C, Crafter C, et al: Blocked autophagy using lysosomotropic agents sensitizes resistant prostate tumor cells to the novel Akt inhibitor AZD5363. Clin Cancer Res 19: 833-844, 2013

86 Cen B, Mahajan S, Wang W and Kraft AS: Elevation of receptor tyrosine kinases by small molecule AKT inhibitors in prostate cancer is mediated by Pim-1. Cancer Res 73: 3402-3411, 2013.

87. Kinkade CW, Castillo-Martin M, Puzio-Kuter A, et al: Targeting AKT/mTOR and ERK MAPK signaling inhibits hormonerefractory prostate cancer in a preclinical mouse model. J Clin Invest 118: 3051-3064, 2008.

88. Tai S, Sun Y, Liu N, et al: Combination of Rad001 (everolimus) and propachlor synergistically induces apoptosis through enhanced autophagy in prostate cancer cells. Mol Cancer Ther 11: 1320-1331, 2012.

89. Festuccia C, Gravina GL, Muzi P, et al: Akt down-modulation induces apoptosis of human prostate cancer cells and synergizes with EGFR tyrosine kinase inhibitors. Prostate 68: 965-974, 2008. 